\section{On the nature of the primacy effect in memory processing: A reply to Gaffan}

\author{
ANTHONY A. WRIGHT \\ and HECTOR C. SANTIAGO \\ University of Texas, Houston, Texas \\ and \\ STEPHEN F. SANDS \\ University of Texas, El Paso, Texas
}

The primacy effect, remembering the first items of a list better than the middle ones, "maintains its reputation as the Chinese puzzle of verbal learning" (Tulving \& Madigan, 1970, p. 454). To this day, there is little concrete evidence as to the cause, although many theories have been proposed to account for it: interference theory by way of a lack of proactive interference (Foucault, 1928; Postman \& Phillips, 1965), endpoint distinctiveness (Bower, 1971; Ebenholtz, 1972; Murdock, 1960), and rehearsal (Atkinson \& Shiffrin, 1968; Waugh \& Norman, 1965), just to name a few. Recently, we (Sands \& Wright, 1980a) showed the first primacy effect for an animal, a rhesus monkey working in a serial-probe recognition (SPR) task. At about the same time, Roberts and Kraemer (1981), using a different species of monkey in a slightly different task, demonstrated a primacy effect too. Thus, we, along with Roberts and Kraemer, felt that the primacy effect in memory processing is characteristic (or at least possible) in primates generally. More recently, we have demonstrated it with pigeons (unpublished as yet), which indicates even wider generality within the animal kingdom.

Gaffan (1983) has made a somewhat different interpretation. He suggested that our monkey primacy effects resulted from a procedural artifact of requiring the monkeys to respond to initiate the list items. Implicit in his suggestion is that our primacy effects are not produced by the same memory processes that produce the primacy effect in human memory experiments. Also implied is that the findings of primacy effects in our monkeys can be dismissed as inconsequential because such effects result from an uninteresting procedural artifact.

The authors gratefully acknowledge the helpful comments made by Michael J. Watkins on an earlier draft of this manuscript. A. A. Wright and H. C. Santiago's mailing address is: University of Texas Health Science Center, Graduate School of Biomedical Sciences, Houston, Texas 77025. S. F. Sand's mailing address is: Department of Psychology, University of Texas at El Paso, El Paso, Texas 79968.
Gaffan argued that the initiating response in our experiment, pushing down on the three-position lever, draws attention to the first list item, makes it more distinctive, and consequently makes it easier to remember. Similar arguments were directed toward Roberts and Kraemer's study. He cites three experiments of his (Gaffan, 1977, 1979; Gaffan \& Weiskrantz, 1980) in which he obtained serial-position functions. None revealed primacy effects, and all of them required the monkeys to initiate every item. According to his argument, all items in his experiment were equally attended to, equally distinctive, and equally well remembered. The causes of Gaffan's failure to find a primacy effect may have to do with his choice of a procedure rather than with any artifact in our procedures. Indeed, we would not expect all memory tests to reveal primacy effects with monkeys; they do not with human subjects. A failure to find a primacy effect does not prove that an animal is not capable of producing a primacy effect; perhaps the proper procedure for revealing a primacy effect just has not yet been discovered. In two of the three experiments (Gaffan, 1979; Gaffan \& Weiskrantz, 1980), there is no a priori reason to expect that his unusual and somewhat complicated procedure should reveal a primacy effect. In the third experiment (Gaffan, 1977), he employed a SPR procedure. We have since replicated this experiment (Sands \& Wright, 1980b, Experiment 3) and also found no primacy effect. It is contrary to his hypothesis that our experiment did not reveal a primacy effect because our monkey initiated the list items, a procedure which, according to Gaffan's responsedependent attentional hypothesis, should have produced one. In both experiments, only three-item list lengths were used. Furthermore, the items in both experiments were drawn from six item pools, which tended to interfere with performance because the items were repeated many times. Our experiment demonstrated the comparatively poor performance with the high (proactive) interference when items were repeated and the much better performance when the items were not repeated. We routinely train our monkeys without interference by using a large item pool (3,000 or more items). Following adequate training, they perform almost as accurately as human subjects in the task. With our monkeys, we have demonstrated $83 \%$ accuracy with 20 -item list lengths, $86 \%$ with 10-item list lengths, and, more recently, even better than $90 \%$ with 10 -item list lengths. We have never failed in training a monkey on the SPR task. We have successfully trained and tested five monkeys on this task. All five have shown robust and reliable primacy effects.

There are advantages to using a memory task that 
has been used to test human recognition memory: (1) The SPR task is a paradigm that has been shown to reveal a primacy effect with human subjects (Jahnke \& Erlick, 1968; Murdock, 1968). Thus, it stands a greater chance than some unproven procedure to reveal a primacy effect with animals. (2) Comparisons can be made with the body of data amassed on human subjects over the years. For example, when the SPR list length is varied from trial to trial, primacy effects are not found (Sternberg, 1966). We also found none when we conducted the variable-list-length SPR experiment (Sands \& Wright, 1982). This is further evidence against Gaffan's response-dependent attentional hypothesis, because both our monkey and human subjects initiated the list, and Gaffan's response-dependent attentional hypothesis would predict that there should have been a primacy effect. (3) Animal and human memory can be directly compared using this task, without the obvious drawbacks of trying to translate between tasks. The SPR task may be unique in this regard. Animals cannot verbally recall items as humans do in recall tasks. Many animal memory tasks (e.g., delayed response) would be inappropriate for use with human subjects because they would make no mistakes.

The SPR task has provided us a tool with which we have begun to explore several aspects of animal memory processing. Among our recent findings is that a variable probe delay differentially affects the primacy and recency portions of the serial-position function. This result is particularly damaging to Gaffan's response-dependent attentional hypothesis because there is no primacy effect at very short probe delays but there is at longer probe delays; in all cases, the monkey makes the same response, pushing down on the lever, to initiate the list items.

Two monkeys were presented with lists of four colored slides, and, after a delay, with a single test item (probe). They had to indicate (by moving a lever) whether or not the probe item matched one of the list items, and they had to push down on the lever to initiate the trial. Probe-delay tests were conducted in 20-trial blocks composed of 10 same trials and 10 different trials. The results showed that with a 0 -sec probe delay (the probe item immediately followed the last list item), there was only a recency effect in the serial-position function (see Figure 1). At probe delays of 1, 2, and $10 \mathrm{sec}$ (the 2-sec results are shown in Figure 1), there were both primacy and recency effects. Finally, at long probe delays of 20 and $30 \mathrm{sec}$ (the 30-sec results are shown in Figure 1), only primacy effects were found in the serial-position function. These trends were highly similar and significant in the individual animals. These results are contrary to Gaffan's hypothesis because the initiation response was required on all trials, no matter what probe delay was to follow. Attention to the first list item should have been as great at the 0 -sec probe delay as at the 30-sec probe delay, but there was no primacy effect in the former and total primacy in the latter. We explained these probe-delay effects (Wright, Santiago, Sands, \& Urcuioli, in press) as a dual process of recovery from retroactive interference (cf. Postman, Stark, \& Fraser, 1968) and loss of a short-term memory storage (cf. Waugh \& Norman, 1965).

We have conducted nearly identical probe-delay

PROBE DELAY

o-sec

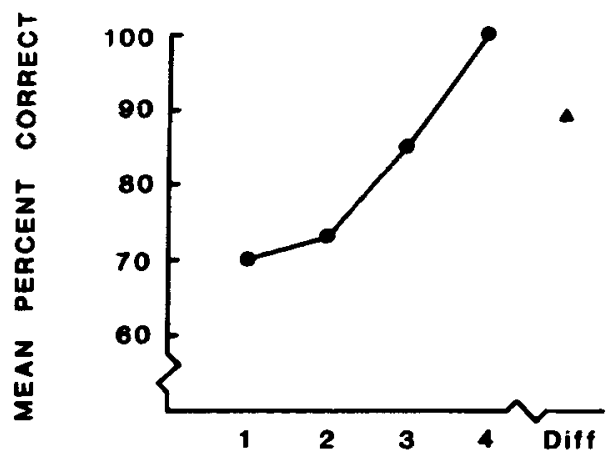

$2-\sec$

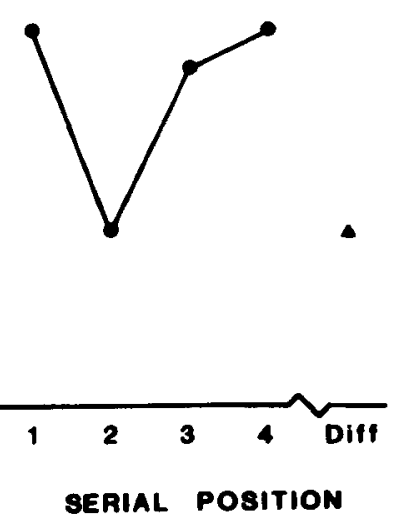

30-sec

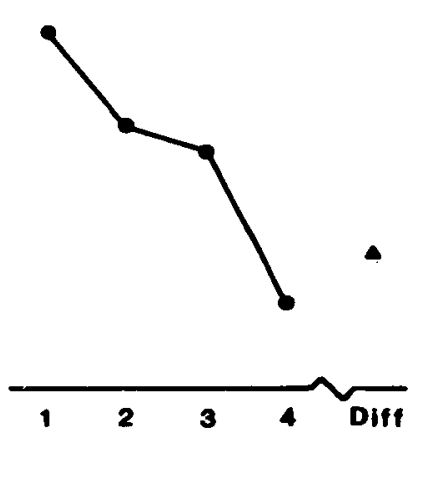

Figure 1. Mean serial-position functions for two monkeys in a four-item serial-probe recognition task (circles). Mean percent correct on different (Diff) trials, on which the probe item matched none of the list items (triangles). The experimental parameters were: 1-sec item viewing time, 1-sec interitem interval, variable probe delay between the last list item (Item 4) and the probe item, reinforcement for all correct responses, and a 10 -sec time-out for errors. 
experiments on human subjects for comparison with probe-delay results from monkeys. Also, we have recently succeeded in training pigeons in the SPR task and have conducted the probe-delay experiments with them too. We find it interesting and important that all three species showed the same basic results: only a recency effect at zero probe delay, both primacy and recency effects at intermediate delays, and only a primacy effect at long probe delays. The only species difference was quantitative (not qualitative): a long delay for pigeons was $10 \mathrm{sec}$, whereas long delays for monkeys and humans were 30 and $40 \mathrm{sec}$, respectively. All three species made a response to initiate the list of items. The pigeons pecked a large window, through which they viewed the slides to initiate the trial. The monkeys and humans pushed down on the three-position lever to initiate the trial. The absence of the primacy effect at zero probe delay and then appearance at longer probe delays for humans and pigeons as well as monkeys further argues against Gaffan's response-dependent attentional hypothesis. Similarity of effects across species argues that the same memory mechanisms in all three species produce the serial-position effects. We believe that whatever factors are responsible for the primacy effects in human memory experiments are likely to be the same factors controlling primacy in our animal memory experiments.

\section{REFERENCES}

Atkinson, R. C., \& Shifrain, R. B. Human memory: A proposed system and its control processes. In $K . W$. Spence and J. T. Spence (Eds.), The psychology of learning and motivation (Vol. 2). New York: Academic Press, 1968.

BowE R, G. H. Adaptation-level coding of stimuli and serial position effects. In M. H. Appley (Ed.), Adaptation-level theory. New York: Academic Press, 1971.

Eeenholtz, S. M. Serial learning and dimensional organization. In G. H Bower (Ed.), The psychology of learning and motivation (Vol. 5). New York: Academic Press, 1972.

Foucault, M. Les inhibitors internes de fixation. Année Psychologique, 1928, 29, 92-112.

Gaffan, D. Recognition memory after short retention intervals in fornix-transected monkeys. Quarterly Journal of Experimental Psychology, 1977, 29, 577-588.

Gafran, D. Acquisition and forgetting in monkeys' memory of informational object-reward associations. Learning and Motivation, 1979, 10, 419-444.

Gaffan, D. A comment on primacy effects in monkeys' memory for lists. Animal Learning \& Behavior, 1983, 11, 144-145.

Gaffan, D., \& Weiskrantz, L. Recency effects and lesion effects in delayed nonmatching to randomly baited samples by monkeys. Brain Research, 1980, 196, 373-386.

JahnKe, J. C., \& ERlick, D. D. Delayed recognition and the serial organization of short-term memory. Journal of Experimental Psychology, 1968, 77, 641-647.

Murdock, B. B., JR. The distinctiveness of stimuli. Psychological Review, 1960, 67, 16-31.

Murdock, B. B., JR. Modality effects in short-term memory: Storage or retrieval? Journal of Experimental Psychology, 1968, 77, 79-86.

Postman, L., \& Phillips, L. W. Short-term temporal changes in free recall. Quarterly Journal of Experimental Psychology, $1965,17,132-138$.

Postman, L., Stark, K., \& Fraser, J. Temporal changes in interference. Journal of Verbal Learning and Verbal Behavior, $1968,7,672-694$.

Roberts, W. A., \& Kraemer, P. J. Recognition memory for lists of visual stimuli in monkeys and humans. Animal Learning \& Behavior, 1981, 9, 587-594.

SAnd8, S. F., \& Wriaht, A. A. Primate memory: Retention of serial list items by a rhesus monkey. Science, 1980, 209, 938-940. (a)

SANDs, S. F., \& Whiaht, A. A. Serial probe recognition performance by a rhesus monkey and a human with 10 - and 20 item lists. Journal of Experimental Psychology: Animal Behavior Processes, 1980, 6, 386-396. (b)

SAnDs, S. F., \& Wright, A. A. Monkey and human pictorial memory scanning. Science, 1982, 216, 1333-1334.

Sternbero, S. High-speed scanning in human memory. Science, $1966,153,652-654$.

Tulvina, E., \& Madionn, S. A. Memory and verbal learning. Annual Review of Psychology, 1970, 21, 437-484.

Waugh, N. C., \& Norman, D. A. Primary memory. Psychological Review, 1965, 72, 89-104.

Wricht, A. A., Santiago, H. C., Sands, S. F., \& Urculoli, P. J. Pigeon and monkey serial probe recognition: Acquisition, strategies, and serial position effects. In $\mathbf{H}$. L. Roitblat, T. Bever, \& H. S. Terrace (Eds.), Animal cognition. Hillsdale, N.J: Erlbaum, in press.

(Manuscript received August 19, 1982; accepted for publication August 21, 1982.) 